\title{
Pengaruh Loyalitas dan Fanatisme Supporter pada Klub terhadap Keputusan Pembelian Merchandise Orisinal: Studi pada Supporter Persela Lamongan
}

\author{
Asma'ul Khomsiyah \\ Sanaji \\ Manajemen, Universitas Negeri Surabaya, Indonesia \\ Korespondensi penulis: sanaji@unesa.ac.id
}

\begin{abstract}
This study aims to investigate the effect of loyalty and fanaticism on supporters' loyalty in purchasing original merchandise. Fanaticism was proposed to mediate the effect of loyalty on purchase. About 100 samples from supporters of Persela Lamongan football club were used to test the proposed model. Data were collected by questionnaire and tested its validity and reliability. We apply Partial Least Square (PLS) method to test the hypothesis. Based on the research results, it could be concluded that fanaticism did not affect purchasing decisions. Meanwhile, it had been proven that supporter loyalty had a positive effect on fanaticism, supporter loyalty had a significant positive effect on purchasing decisions. It means that fanaticism was not able to strengthen the influence of supporter loyalty on purchasing decisions.
\end{abstract}

Keywords: Fanaticism; Loyalty; Original merchandise; Purchasing Decision; Supporter.

\begin{abstract}
Abstrak. Penelitian ini bertujuan untuk menguji pengaruh loyalitas dan fanatisme terhadap pembelian merchandise orisinal klub sepak bola. Fanatisme diproposisikan sebagai variabel intervening yang menjembani pengaruh loyalitas terhadap keputusan pembelian. Sejumlah 100 pendukung Persela Lamongan dijadikan sampel untuk menguji model penelitian ini. Data dikumpulkan melalui penyebaran kuesioner dan dilakukan uji validitas dan reliabilitasnya. Pengujian hipotesis menggunakan Partial Least Square (PLS). Hasil penelitian ini menemukan bahwa fanatisme tidak berpengaruh signifikan terhadap keputusan pembelian. Sementara itu, loyalitas supporter terbukti berpengaruh signifikan terhadap fanatisme, dan loyalitas supporter berpengaruh signifikan terhadap keputusan pembelian, sedangkan fanatisme tidak mampu menguatkan pengaruh loyalitas supporter terhadap keputusan pembelian.
\end{abstract}

Kata kunci: Fanatisme; Loyalitas; Barang dagangan asli; Keputusan Pembelian; Pendukung.

\begin{tabular}{|c|c|c|}
\hline $\begin{array}{l}\text { Article Info: } \\
\text { Received· Novemher } 112020\end{array}$ & & \\
\hline $\begin{array}{l}\text { Received: November 11, } 2020 \\
\text { DOI: http://dx.doi.org/10.30588 }\end{array}$ & $\begin{array}{l}\text { Accepted: February 8, } 2020 \\
\text {.v10i2.756 }\end{array}$ & Available online: February 27, \\
\hline
\end{tabular}




\section{PENDAHULUAN}

Di dalam dunia bisnis terdapat dua jenis konsumen, yaitu konsumen yang lebih memilih untuk membeli barang palsu dan konsumen yang lebih memilih membeli barang orisinal. Pemalsuan produk telah berkembang sejak tahun 1970-an, ketika Levi menemukan sejumlah besar jeans palsu yang membawa logo merek dagang mereka di Asia Tenggara (Phau, Sequeira, \& Dix, 2009). Perdagangan barang palsu yang meningkat mengakibatkan kerusakan ekonomi semakin meningkat pula (Huynh \& Wilson, 2014). Banyak alasan untuk memutuskan keputusan memilih produk antara yang orisinal atau palsu. Dua alasan keputusan pemilihan tersebut di antaranya adalah loyalitas dan fanatisme terhadap produk atau yang berkaitan dengannya. Membeli produk orisinal atau pun produk palsu dapat dipengaruhi oleh loyalitas dan fanatisme (Samra \& Wos, 2015; Kusuma, 2016). Dengan adanya loyalitas dan fanatisme di dalam diri konsumen, maka ia dapat memutuskan untuk membeli barang dagangan orisinal.

Loyalitas dan fanatisme supporter atau pendukung juga terjadi pada klub Persatuan Sepak Bola Lamongan (Persela). Persela merupakan sebuah klub sepak bola Indonesia yang bermarkas di Lamongan, Jawa Timur. Supporter Persela yang menamakan diri LA Mania dan Curva Boys 1967 sangat loyal dan fanatik kepada klub Persela. Supporter Persela sangat setia dan mereka akan melakukan banyak hal, baik yang konstruktif maupun destruktif untuk kemenangan Persela. Loyalitas dan fanatisme yang ada pada diri pendukung klub sepak bola menjadikan mereka bersedia secara sukarela membeli berbagai bentuk merchandise yang berhubungan dengan klub sepak bola idolanya (Rizki \& Utomo, 2017), sehingga banyak dari pendukung atau fans setia yang membeli merchandise tersebut. Hal ini juga didukung oleh banyaknya supporter atau penonton pertandingan yang melibatkan klub Persela. Jumlah penonton pertandingan Persela menempati 10 besar jumlah penonton terbanyak dalam Liga Indonesia tahun 2019 (Wicaksono, 2019). Supporter Persela memiliki 86 koordinator wilayah (korwil). Supporter Persela pernah ditetapkan sebagai pendukung tim sepak bola terbaik pada Indonesian Super Ligue (ISL) periode tahun 2008-2009 (Sulfiyanto, 2017). Supporter Persela memiliki loyalitas tinggi kepada tim sepak bola Persela. Hal tersebut terbukti ketika Persela bertanding, baik laga kandang maupun tandang (Mahmudah \& Liliana, 2018). Semakin banyak jumlah pendukung Persela, maka peluang penjualan merchandise Persela juga semakin tinggi.

Manajemen Persela sangat menyadari bahwa loyalitas dan fanatisme supporter Persela merupakan potensi yang perlu dikelola untuk kemajuan klub. Selain memberikan dukungan semangat kepada para pemain, loyalitas dan fanatisme pendukung juga dapat dimemanfaatkan untuk mendorong penjualan merchandise sebagai salah satu sumber pemasukan bagi klub. Menjual merchandise adalah salah satu cara klub sepak bola mendapatkan peluang bisnis dengan adanya pendukung klub sepak bola atau komunitas bola (Rizki \& Utomo, 2017). Merchandise klub dapat dijual secara online dan konvensional. Merchandise yang ditawarkan berupa jersey dan training kit seperti topi, celana, rompi, kaos, dan jaket atau sweater. Merchandise tersebut dijual dengan harga yang terjangkau di dua toko yang berada di Lamongan Plaza dan Paciran, serta melalui media sosial Instagram.

Loyalitas yang dimiliki oleh supporter klub sepak bola akan mendorong keinginan mereka untuk mendukung tim yang diidolakan. Semakin tinggi loyalitas yang dimiliki oleh supporter, maka dukungan yang diberikan kepada tim idola juga semakin besar. 
Salah satu cara untuk mendukung tim idola adalah membeli original merchandise, karena hal itu merupakan wujud loyalitas yang mereka miliki (Setiawan \& Saraswati, 2017; Aswanto \& Nurchayati, 2020). Sementara itu, fanatisme mempengaruhi penggemar sepak bola berperilaku semirip mungkin dengan anggota tim sepak bola favoritnya atau mendorongnya untuk menunjukkan rasa cintanya kepada tim sepak bola melalui beragam cara (Kusuma, 2016). Wujud ekspresi fanatisme pendukung tim sepak bola tersebut semakin meningkat, mulai dari rasa cinta yang berlebihan pada tim sepak bola favoritnya hingga teraktualisasi dalam perilaku pembelian atau penggunaan atribut tim sepak bola mereka. Hal tersebut menunjukkan bahwa fanatisme mampu mendorong supporter tim sepak bola untuk membelanjakan uangnya guna mendapatkan merchandise tim (Mubina, Amirudin, \& Lathifah, 2020).

Terkait dengan hubungan antara loyalitas dan fanatisme suppoter dengan keputusan pembelian merchandise, beberapa penelitian sebelumnya menyatakan bahwa loyalitas dan fanatisme memiliki pengaruh positif terhadap pembelian merchandise. Loyalitas mempunyai pengaruh positif terhadap perilaku sukarela. Perilaku sukarela yang dimaksud adalah kesetiaan mendukung tim sepak bola dengan menonton setiap pertandingan tim idolanya tersebut atau membeli merchandise yang dapat mengidentifikasi tim tersebut. Penelitian Muslich dan Dewi, (2017) menyatakan fanatisme mempunyai pengaruh terhadap perilaku konsumtif supporter Lazio di Surabaya. Kecintaan terhadap sebuah klub sepak bola dapat mendorong supporter untuk membeli produk-produk yang berkaitan dengan klub kesayangannya. Fanatisme mempunyai pengaruh kuat terhadap perilaku konsumtif supporter (Muslich \& Dewi, 2017).

Loyalitas dan fanatisme suppoter klub sepak bola sebagai sebuah fenomena yang diharapkan mampu menjadi faktor pendorong penjualan merchandise ternyata belum tentu sesuai harapan. Loyalitas dan fanatisme supporter tidak secara otomatis mendorong supporter melakukan pembelian merchandise orisinal yang ditawarkan oleh klub. Meskipun supporter Persela terlihat loyal dan fanatik, masih banyak supporter Persela yang tidak membeli dan memakai atribut atau merchandise orisinal di Persela Store. Hal ini menjadi kajian utama dalam penelitian ini mengingat Persela Store telah menetapkan harga yang terjangkau untuk berbagai merchandise yang ditawarkannya, Namun, masih banyak supporter Persela yang memilih untuk tidak membeli merchandise orisinal tersebut (Ceritajersey.com, 2019). Berdasarkan telaah studi sebelumnya dan fenomena yang terjadi pada supporter Persela tersebut mengindikasikan adanya ketidakkonsistenan, sehingga penelitian ini penting dilakukan dengan tujuan untuk menganalisis pengaruh loyalitas dan fanatisme supporter Persela terhadap pembelian merchandise orisinal klub tersebut.

\section{KAJIAN TEORITIS}

\section{Loyalitas Supporter}

Terdapat dua jenis penonton dalam kompetisi olahraga. Tipe pertama adalah pecinta olahraga dan yang kedua adalah penggemar (Bauer, Stokburger-Sauer, \& Exler, 2008). Berdasarkan karakteristiknya, supporter adalah pecinta olahraga yang juga menganggap dirinya memiliki hubungan kuat dengan klub yang mereka dukung, sedangkan pecinta olahraga biasa hanya menghadiri pertandingan karena menyukai jenis olahraga tertentu. Loyalitas dapat diartikan sebagai kepatuhan maupun kesetiaan. Artinya, loyalitas pada klub sepak bola adalah kesetiaan fans atau supporter sepak bola 
terhadap klub sepak bola yang diidolakannya. Istilah "loyalitas penggemar" mengacu pada output dari konsistensi dan dedikasi untuk mendukung dan menunjukkan komitmen kepada tim (Johnston, 2004). Secara khusus, literatur pemasaran olahraga saat ini menggambarkan karakteristik loyalitas penggemar dalam tiga pendekatan, yaitu kognitif, sikap, dan perilaku (Maderer \& Holtbrügge, 2019). Perilaku supporter berbeda dengan pecinta olahraga (Anam \& Supriyadi, 2018).

Loyalitas supporter olahraga penting untuk dicapai karena penggemar olahraga yang setia merupakan konsumen unik (Anam \& Supriyadi, 2018). Komitmen mereka terhadap tim olahraga dapat dikatakan tidak tertandingi dibandingkan sektor bisnis atau rekreasi lainnya (Tapp \& Clowes, 2002). Seseorang yang menganggap dirinya sebagai pendukung klub olahraga tertentu akan menunjukkan perilaku sebagai berikut: keinginan untuk menghadiri setiap pertandingan klub favorit mereka di stadion, keinginan untuk terus memperbarui berita tentang klub favorit mereka, dan keinginan untuk membeli produk dan atribut klub favorit mereka (Rohman, 2019). Sementara itu, dimensi loyalitas supporter klub sepak bola meliputi: (1) membeli tiket pertandingan tim favorit; (2) berulang-ulang menghadiri pertandingan tim favorit; (3) menonton pertandingan tim favorit dari televisi; (4) berbicara tentang tim favorit; dan (5) berbelanja produk-produk atau merchandise dari tim favorit mereka (Elahi, Mahmoudi, \& Yazdi, 2018).

\section{Fanatisme Supporter}

Fanatisme merupakan keyakinan atau kepercayaan yang sangat kuat terhadap klub sepak bola (Chaplin, 2008). Fanatisme menunjukkan tingkat intensitas seseorang sebagai penggemar sesuatu (Thorne \& Bruner, 2006). Fanatisme muncul pada kelompok kepenggemaran atau fandom (Samra \& Wos, 2015) yang melibatkan subkultur sekelompok individu yang memiliki pikiran yang sama dengan peminatan yang sama juga. Penggemar menunjukkan tingkat keterlibatan internal lebih tinggi daripada bukan penggemar dan siap mengubah gaya hidup mereka untuk mengakomodasi fanatismenya (Redden \& Steiner, 2000; Thorne \& Bruner, 2006). Emosi yang terkait dengan fanatisme dibentuk oleh perilaku penggemar mulai dari kegiatan disfungsional yang obsesif dan kompulsif hingga tampilan yang tidak terlalu berlebihan (Fillis \& Mackay, 2014). Supporter fanatik menunjukkan kecintaan yang kuat pada klub sepak bola dan mereka tetap setia meskipun kinerja klub tersebut buruk (Samra \& Wos, 2015).

Konsumen fanatik mengindikasikan "extreme devotion to a brand" yaitu merek menjadi bagian penting yang memiliki pengaruh dalam kehidupan konsumen (Chung, Farrelly, Beverland, \& Karpen, 2018). Apa pun akan dijalankan konsumen untuk tetap memakai dan memiliki merek tersebut, sehingga konsumen telah mencapai pada kondisi pemujaan terhadap suatu merek (cult brand). Supporter fanatik sebagai konsumen menunjukkan kekaguman sejati terhadap suatu merek atau produk klub sepak bola yang digemarinya, pengabdian, semangat, dan antusiasme mereka sering dianggap menular untuk menarik pelanggan baru atau supporter baru (Belk, 2004). Seorang penggemar adalah individu dengan koneksi abadi terhadap subyek tertentu, sedangkan fanatisme adalah taraf intensitas yang bersangkutan (Thorne \& Bruner, 2006). Fanatisme seorang supporter dapat diukur dari karakteristik kuat dalam hal keterlibatan emosional (perasaan senang, komitmen, dan kesetiaan) (Chung, Beverland, Farrelly, \& Quester; 2008), dan pembelaan pada klub (Habibie, 2015). 


\section{Keputusan Pembelian}

Keputusan pembelian adalah keputusan konsumen untuk melakukan suatu pembelian produk setelah sebelumnya melakukan pemikiran layak atau tidaknya melakukan pembelian produk itu dengan mempertimbangkan informasi yang diketahui dengan fakta tentang produk tersebut sesudah menyaksikannya (Kotler \& Keller, 2016). Hasil pemikiran tersebut menurut Zeithmal dipengaruhi oleh rasa takut atas keinginan konsumen untuk melakukan pembelian sebagai pilihan atas istilah keputusan pembelian (Setiadi, 2003). Keputusan pembelian konsumen merupakan perilaku yang diperlihatkan oleh unit-unit pengambilan keputusan dalam pembelian, pemakaian, dan pembuangan produk (Khuong \& Duyen, 2016). Menurut Kotler dan Keller (2016) dimensi keputusan pembelian meliputi keputusan tentang pilihan produk, keputusan tentang merek, keputusan tentang saluran pembelian, keputusan tentang jumlah produk, keputusan tentang waktu pembelian, dan keputusan tentang pembayaran.

\section{Hubungan Antarvariabel}

\section{Loyalitas dan Fanatisme}

Studi literatur pemasaran mengungkapkan adanya hubungan erat antara fanatisme dan loyalitas merek, loyalitas membeli, dan keinginan untuk suatu produk/kelompok produk (Deveci \& Ercis, 2017). Loyalitas merupakan suatu kondisi individu yang memiliki sikap positif terhadap suatu merek (Kotler \& Keller, 2017). Merek dapat berwujud tim sepak bola, sedangkan individu dapat berupa supporter atau pendukung tim sepak bola (Kaynak, Salman, \& Tatoglu, 2008). Ketika sebuah tim olahraga dievaluasi sebagai produk yang akan dipasarkan, maka loyalitas tim berarti mempertahankan loyalitas kepada tim tertentu (Tokmak \& Aksoy, 2016). Dengan demikian, loyalitas supporter adalah kesetiaan pendukung terhadap tim sepak bola. Supporter yang memiliki komitmen kuat akan mendorongya menjadi supporter yang fanatik. Supporter yang terlalu loyal akan berubah menjadi tidak rasional dalam mencintai suatu tim sepak bola.

Seseorang yang memiliki fanatisme cenderung tidak mampu untuk berpikir rasional dan mengabaikan hal-hal lainnya (Goddard, 2001). Sementara itu, fanatisme adalah bentuk unik dari kesetiaan yang diindikasikan dari taraf komitmen, kesetiaan, dedikasi, semangat, keterikatan emosional, antusiasme, serta engagement yang kuat dan ekstrim (Bristow \& Sebastian, 2001; Cova \& Cova, 2002; Funk, Mahony, \& Ridinger, 2002). Loyalitas dapat menjadikan pelanggan bersikap fanatik (Yuniarti \& Ariyanto, 2018). Dengan demikian, tinggi rendahnya loyalitas supporter akan menentukan perubahan ke arah fanatisme. Loyalitas yang tinggi akan mendorong pada fanatisme yang tinggi. Sebaliknya, loyalitas supporter yang rendah akan sulit untuk mendorong terbentuknya fanatisme. Berdasarkan uraian tersebut, maka rumusan hipotesis kesatu (H1) dalam penelitian ini adalah:

\section{H1: Loyalitas berpengaruh terhadap fanatisme.}

\section{Loyalitas dan Keputusan Pembelian Merchandise}

Menurut Kotler dan Keller (2016), loyalitas merupakan komitmen konsumen yang dijaga kuat untuk melakukan pembelian atau menjadi pelanggan produk, baik berupa barang atau jasa tertentu di waktu selanjutnya walaupun ia mendapatkan dampak situasi dan upaya pemasaran yang menimbulkan perubahan perilaku. Loyalitas yang ada pada 
suatu tim sepak bola akan mendorong individu (supporter) untuk membeli suatu produk yang dihasilkan atau diproduksi oleh tim sepak bola tersebut. Individu atau supporter yang loyal merasa berpersepsi bahwa membeli merchandise adalah wujud rasa setianya pada tim sepak bola yang didukungnya. Loyalitas supporter olahraga memiliki makna penting untuk dicapai, karena penggemar olahraga yang setia adalah konsumen unik. Komitmen mereka terhadap tim olahraga tidak tertandingi di sektor bisnis atau rekreasi yang lain (Tapp \& Clowes, 2002). Loyalitas terhadap suatu tim olahraga memiliki pengaruh positif yang signifikan terhadap perilaku konsumsi dan sikap penggemar. Hal ini menyiratkan bahwa untuk menghasilkan loyalitas tim olahraga yang maksimal atau dukungan berbasis penggemar merupakan tujuan penting bagi setiap tim olahraga (Da Silva \& Casas, 2017).

Semakin setia seorang penggemar kepada suatu tim olahraga, maka mereka akan semakin terlibat untuk mengonsumsi produknya. Penggemar yang sangat setia cenderung melihat pengeluaran mereka sebagai cara untuk mendukung tim, bukan sekedar membayar uang untuk mendapatkan barang atau jasa. Hal ini menyebabkan banyak penggemar menjadi kurang sensitif terhadap harga saat membeli barang dagangan tim atau pemainnya (Piipponen, 2011). Wymer dan Rundle-Thiele (2016) menyatakan bahwa loyalitas pendukung adalah prediktor yang baik terhadap perilaku sukarela. Pendukung yang loyal akan secara sukarela melakukan pembelian terhadap merchandise yang dipasarkan oleh tim sepak bola yang didukungnya. Hal ini berarti, semakin tinggi loyalitas pendukung, maka semakin tinggi pula kecenderungan untuk memutuskan pembelian produk merchandise yang dikeluarkan oleh tim sepak bola tersebut. Berdasarkan uraian tersebut, maka rumusan hipotesis kedua $(\mathrm{H} 2)$ dalam penelitian ini adalah:

\section{H2: Loyalitas berpengaruh terhadap keputusan pembelian merchandise.}

\section{Fanatisme dan Keputusan Pembelian Merchandise}

Fanatisme mampu mempengaruhi individu penggemar sepak bola untuk memiliki perilaku yang semirip mungkin dengan tim sepak bola idolanya atau mendukung para supporternya untuk menunjukkan rasa cintanya dengan tim sepak bola melalui beragam ekspresi. Supporter fanatik sebagai konsumen akan menunjukkan kekaguman sejati terhadap merek atau produk klub sepak bola yang digemari, pengabdian, semangat, dan antusiasme mereka sering menular dalam menarik pelanggan baru atau supporter baru (Belk, 2004). Wujud ekspresi fanatisme supporter tim sepak bola yang meningkat mulai dari rasa cinta yang berlebihan pada klub sepak bola idolanya sampai terasing dalam sebuah perilaku pembelian atau pun penggunaan atribut tim sepak bolanya. Hal ini menunjukkan bahwa fanatisme mampu mendorong supporter tim sepak bola untuk membelanjakan uangnya untuk mendapatkan merchandise tim (Mubina et al., 2020). Perilaku membeli merchandise tim merupakan peran penting supporter dalam kegiatan yang berkaitan dengan transaksi (Yoshida, Gordon, Nakazawa, \& Biscaia, 2014). Transaksi yang dimaksud tersebut adalah transaksi pembelian merchandise orisinal. Penelitian Muslich \& Dewi (2017). Menyebutkan bahwa fanatisme mempunyai pengaruh terhadap perilaku konsumtif supporter Lazio di Surabaya. Kecintaan terhadap suatu klub sepak bola mendorong seorang supporter untuk membeli produk-produk yang berkaitan dengan klub kesayangannya. Berdasarkan uraian tersebut, maka hipotesis ketiga (H3) dalam penelitian ini dirumuskan sebagai berikut: 


\section{H3: Fanatisme berpengaruh terhadap keputusan pembelian merchandise.}

\section{Kerangka Konseptual}

Berdasarkan kajian teoritis dan hubungan antarvariabel, serta hipotesis yang diajukan dalam penelitian ini, maka model penelitian ini diilustrasikan pada Gambar 1 .

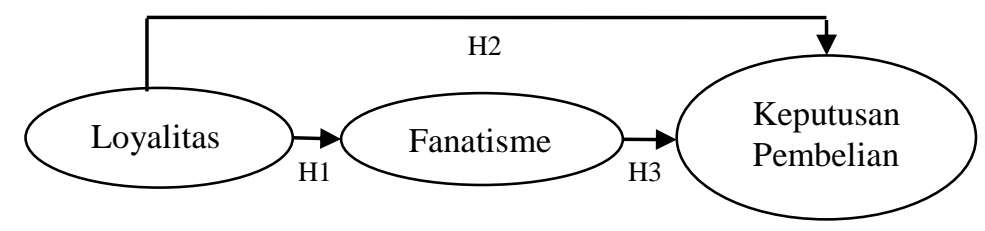

Gambar 1. Model Penelitian

\section{METODE PENELITIAN}

Penelitian ini merupakan penelitian kuantitatif dengan metode korelasional, yakni meneliti pengaruh loyalitas dan fanatisme supporter pada klub Persela terhadap keputusan pembelian merchandise orisinal Persela Store. Data penelitian ini merupakan jawaban responden atas pernyataan dalam kuesioner yang disampaikan kepada supporter Persela Lamongan terpilih. Sumber data dalam penelitian ini merupakan sumber data primer dan sumber data sekunder. Populasi penelitian ini adalah semua supporter klub sepak bola Persela Lamongan yang jumlahnya tidak diketahui secara pasti. Teknik sampling yang digunakan dalam penelitian ini adalah purposive sampling dengan kriteria responden telah menjadi supporter Persela minimal dua tahun terakhir, serta bersedia mengisi kuesioner secara lengkap. Sampel yang digunakan dalam penelitian ini sebanyak 100 responden yang merupakan supporter Persela. Penelitian ini dilaksanakan di Gerai Persela Store yang berlokasi di Lamongan Plaza, 1B1-1B5, Lamongan, Jawa Timur.

Penelitian ini menggunakan instrumen kuesioner tertutup, yakni kuesioner yang respondennya memberikan respon jawaban berupa tanda pada pilihan jawaban yang mereka anggap paling tepat. Variabel loyalitas supporter diukur menggunakan dasar dimensi kesetiaan berulang, ketahanan, dan kemauan mereferensikan (Kotler \& Keller, 2016). Sementara itu, pengukuran terhadap variabel fanatisme supporter yang meliputi perasaan senang dengan klub, rasa kebanggaan, pembelaan (dukungan dan keyakinan pada kondisi apapun), dan kesetiaan kapanpun (Chung, et.al., 2008; Habibie, 2015). Selanjutnya, pengukuran variabel keputusan pembelian yang meliputi dimensi pilihan produk, merek, saluran pembelian, jumlah produk, dan pembayaran (Kotler \& Keller, 2016).

Teknik pengumpulan data dilakukan melalui pendistribusian kuesioner kepada 100 responden supporter Persela. Kuesioner disebarkan kepada responden secara online. Data penelitian ini dianalisis menggunakan metode statisik dengan Partial Least Square (PLS). Penggunaan PLS adalah untuk memprediksi model path yang bisa digunakan untuk model yang kompleks meliputi banyak variabel laten dan manifest tanpa mengalami kendala estimasi data dan bisa juga digunakan saat sebaran data sangat miring atau tidak terdistribusi secara nomal ke semua nilai meannya (Ghozali \& Latan, 
2015). Menurut Ghozali dan Latan (2015), PLS lebih memiliki sifat predictive model, sehingga teknik tersebut dapat digunakan untuk memprediksi hasil di masa depan.

\section{HASIL DAN PEMBAHASAN}

Data penelitian ini didapat dari kuesioner yang sudah diisi oleh responden melalui google form. Setelah terkumpul terdapat 100 responden dilakukan verifikasi dan diperoleh 100 kuesioner dinyatakan benar dan lengkap. Selanjutnya dilakukan olah data dan penyajian hasilnya.

\section{Karakteristik responden}

Berdasarkan data pada Tabel 1, mayoritas responden berjenis kelamin laki-laki (87\%). Selanjutnya, mayoritas usia responden berada pada kisaran 26-35 tahun (36\%). Sebagian besar responden bekerja di sektor swasta (37\%). Mayoritas responden telah menjadi supporter Persela selama kurun waktu 5-10 tahun (35\%).

Tabel 1. Karakteristik Responden

\begin{tabular}{|c|c|c|c|c|c|c|c|c|c|c|c|}
\hline \multicolumn{3}{|c|}{ Jenis Kelamin } & \multicolumn{3}{|c|}{ Usia } & \multicolumn{3}{|c|}{ Pekerjaan } & \multicolumn{3}{|c|}{ Lama Menjadi Supporter } \\
\hline $\begin{array}{c}\text { Jenis } \\
\text { Kelamin }\end{array}$ & Jumlah & $\%$ & $\begin{array}{c}\text { Usia } \\
\text { (tahun) }\end{array}$ & Jumlah & $\%$ & Pekerjaan & Jumlah & $\%$ & $\begin{array}{c}\text { Lama } \\
\text { (tahun) }\end{array}$ & Jumlah & $\%$ \\
\hline Laki-laki & 87 & 87 & $17-25$ & 32 & 32 & Pelajar/Mahasiswa & 34 & 34 & $2-5$ & 27 & 27 \\
\hline \multirow[t]{4}{*}{ Perempuan } & 13 & 13 & $26-35$ & 36 & 36 & Swasta & 37 & 37 & $5-10$ & 35 & 35 \\
\hline & & & $36-45$ & 15 & 15 & Wiraswasta & 11 & 11 & $11-15$ & 21 & 21 \\
\hline & & & $>45$ & 17 & 17 & TNI/Polri/ PNS & 5 & 5 & $16-20$ & 10 & 10 \\
\hline & & & & & & Lain-lain & 12 & 12 & $>20$ th & 7 & 7 \\
\hline Total & 100 & 100 & Total & 100 & 100 & Total & 100 & 100 & Total & 100 & 100 \\
\hline
\end{tabular}

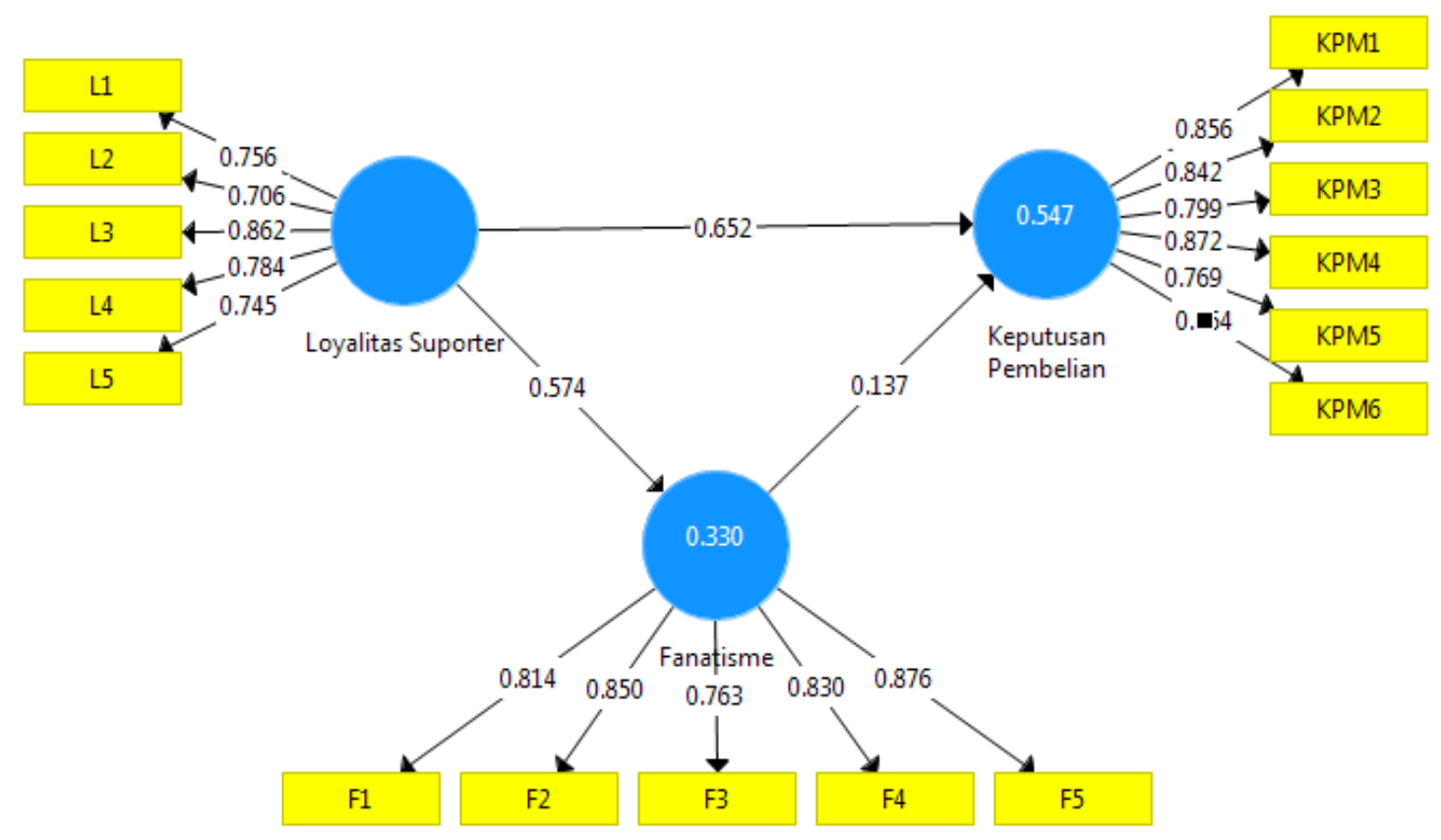

Gambar 2. Hasil Analisis PLS 


\section{Uji Model Pengukuran (Outer Model)}

Model penelitian ini dianalisis menggunakan Partial Least Square (PLS) dengan bantuan software SmartPLS 3.0. Yang diuji dalam pengukuran ini antara lain validitas konvergen, validitas diskriminan, dan reliabilitas.

\section{Uji Validitas}

Berdasarkan hasil analisis pada Gambar 2, seluruh indikator mempunyai loading factor lebih tinggi dari 0,7. Untuk menguji discriminant validity, penelitian ini menggunakan nilai cross loading. Nilai cross loading masing-masing indikator dapat dilihat pada Tabel 2. Masing-masing indikator pada variabel penelitian memiliki nilai cross loading terbesar pada variabel yang dibentuknya dibandingkan dengan nilai cross loading pada variabel lainnya. Dengan demikian, indikator-indikator yang digunakan dalam penelitian ini telah memiliki discriminant validity yang baik dalam menyusun variabelnya masing-masing (Ghozali \& Latan, 2015).

Tabel 2. Uji Validitas Diskriminan Berdasarkan Kriteria Cross Loading

\begin{tabular}{|c|c|c|c|}
\hline Variabel & Fanatisme & $\begin{array}{l}\text { Loyalitas } \\
\text { Supporter }\end{array}$ & $\begin{array}{l}\text { Keputusan } \\
\text { Pembelian } \\
\end{array}$ \\
\hline $\begin{array}{l}\text { Saya merasa senang menjadi pendukung Persela } \\
\text { Lamongan. }\end{array}$ & $\mathbf{0 , 8 1 4}$ & 0,381 & 0,384 \\
\hline Saya bangga sebagai pendukung Persela Lamongan. & $\mathbf{0 , 8 5 0}$ & 0,451 & 0,425 \\
\hline $\begin{array}{l}\text { Saya memberikan dukungan kepada Persela Lamongan } \\
\text { dalam situasi apa pun. }\end{array}$ & 0,763 & 0,524 & 0,407 \\
\hline $\begin{array}{l}\text { Saya yakin dengan Persela Lamongan dalam kondisi apa } \\
\text { pun. }\end{array}$ & $\mathbf{0 , 8 3 0}$ & 0,503 & 0,491 \\
\hline Saya setia dengan Persela Lamongan sampai kapan pun. & $\mathbf{0 , 8 7 6}$ & 0,494 & 0,397 \\
\hline Saya membeli tiket pertandingan Persela Lamongan. & 0,391 & 0,756 & 0,510 \\
\hline $\begin{array}{l}\text { Saya berulang kali menghadiri pertandingan Persela } \\
\text { Lamongan. }\end{array}$ & 0,406 & 0,706 & 0,596 \\
\hline $\begin{array}{l}\text { Saya menonton pertandingan Persela Lamongan dari } \\
\text { televisi. }\end{array}$ & 0,522 & 0,862 & 0,653 \\
\hline Saya berbicara dengan teman tentang Persela Lamongan. & 0,478 & $\mathbf{0 , 7 8 4}$ & 0,552 \\
\hline $\begin{array}{l}\text { Saya membeli produk-produk atau merchandise Persela } \\
\text { Lamongan. }\end{array}$ & 0,403 & 0,745 & 0,493 \\
\hline $\begin{array}{l}\text { Saya membeli semua merchnadise orisinal Persela } \\
\text { Lamongan yang diproduksi oleh Manajemen Persela } \\
\text { Lamongan. }\end{array}$ & 0,400 & 0,628 & $\mathbf{0 , 8 5 6}$ \\
\hline $\begin{array}{l}\text { Saya membeli semua merchnadise orisinal yang berkaitan } \\
\text { dengan Persela Lamongan. }\end{array}$ & 0,450 & 0,608 & 0,842 \\
\hline $\begin{array}{l}\text { Saya membeli merchnadise orisinal Persela Lamongan di } \\
\text { store resminya. }\end{array}$ & 0,508 & 0,655 & 0,799 \\
\hline $\begin{array}{l}\text { Saya berulang kali membeli merchnadise orisinal Persela } \\
\text { Lamongan. }\end{array}$ & 0,404 & 0,555 & 0,872 \\
\hline $\begin{array}{l}\text { Saya membeli merchnadise orisinal Persela Lamongan } \\
\text { setiap ada produk baru yang dikeluarkan Manajemen } \\
\text { Persela Lamongan. }\end{array}$ & 0,325 & 0,516 & 0,769 \\
\hline $\begin{array}{l}\text { Saya membeli merchnadise orisinal Persela Lamongan } \\
\text { meskipun dengan harga yang lebih tinggi dibandingkan } \\
\text { merchnadise Persela Lamongan non-orisinal. }\end{array}$ & 0,400 & 0,602 & 0,764 \\
\hline
\end{tabular}

Sumber: Data primer diolah (2020). 
Metode lain untuk mengevaluasi validitas diskriminan adalah mengkomparasikan akar kuadrat nilai average variance extracted (AVE) dari setiap construct dengan korelasi antara satu construct dan construct lainnya dalam model, sehingga bisa dinyatakan mempunyai nilai validitas diskriminan yang baik. Berdasarkan hasil pengujian, nilai AVE masing-masing variabel adalah Fanatisme $(0,685)$, Loyalitas Supporter $(0,669)$, dan Keputusan Pembelian (0,597). Ketiga nilai AVE tersebut lebih tinggi daripada 0,5, sehingga construct dalam model ini memenuhi kriteria validitas diskriminan.

\section{Uji Reliabilitas}

Hasil analisis pada Tabel 3 menunjukkan bahwa keandalan hasil uji komposit dan Cronbach alpha memiliki nilai yang baik. Hal tersebut dikarenakan semua variabel laten mempunyai composite reliability dan Cronbach alpha $\geq 0,70$ (Ghozali \& Latan, 2015). Jadi, semua variabel dalam penelitian ini adalah variabel laten.

Table 3. Hasil Uji Composite Reliability dan Uji Cronbach Alpha

\begin{tabular}{lccl}
\hline \multicolumn{1}{c}{ Variabel } & Composite Reliability & Cronbach's Alpha & Remark \\
\hline Fanatisme & 0,916 & 0,885 & Reliable \\
\hline Loyalitas Supporter & 0,924 & 0,901 & Reliable \\
\hline Keputusan Pembelian & 0,880 & 0,830 & Reliable \\
\hline
\end{tabular}

Sumber: Data primer diolah (2020).

\section{Uji Kelayakan Model}

Pengujian kelayakan model menggunakan pendekatan global goodness of fit index (Global GoF) dengan cara mencari nilai rata-rata geometrik $\mathrm{R}^{2}$ variabel dependen dan average variance extracted (AVE) setiap variabel laten (Tenenhaus, Vinzi, Chatelin, \& Lauro, 2005). Hasil uji kelayakan model disajikan pada Tabel 4.

Tabel 4. Hasil Uji Kelayakan Model

\begin{tabular}{lccccc}
\hline Latent variable & $\begin{array}{c}\text { Jumlah } \\
\text { indikator }\end{array}$ & AVE & $\begin{array}{c}\text { Jumlah } \\
\text { terbobot }\end{array}$ & $\mathbf{R}^{\mathbf{2}}$ & $\begin{array}{c}\text { Global } \\
\text { GoF }\end{array}$ \\
\hline Loyalitas supporter & 5 & 0,669 & 3,345 & & \\
\hline Fanatisme & 5 & 0,685 & 3,425 & 0,330 & \\
\hline Keputusan Pembelian & 6 & 0,597 & 3,582 & 0,547 & \\
\hline Total & 11 & & 7,007 & 0,877 & \\
Average & & & 0,637 & 0,439 & $\mathbf{0 , 5 2 9}$ \\
\hline
\end{tabular}

Sumber: Data primer diolah (2020).

Global GoF mengkombinasikan variasi yang dijelaskan oleh model pengukuran dan model struktural. Nilai global GoF sebesar 0,529 yang dapat diartikan bahwa 52,9\% variasi model dapat dijelaskan oleh data sampel penelitian ini. Model pengaruh loyalitas terhadap fanatisme memberikan nilai R-square sebesar 0,330 yang dapat diinterpretasikan bahwa variabilitas construct fanatisme yang dapat dijelaskan oleh variabilitas construct loyalitas sebesar 33\%, sedangkan 77\% dijelaskan oleh variabel lain di luar model tersebut. Selanjutnya, model pengaruh loyalitas dan fanatisme terhadap keputusan pembelian memberikan nilai R-square sebesar 0,547 yang diinterpretasikan bahwa variabilitas construct keputusan pembelian dapat dijelaskan oleh variabilitas construct 
loyalitas dan fanatisme sebesar 54,7\%, sedangkan 45,3\% dijelaskan oleh variabel lain di luar model tersebut.

\section{Hasil Uji Hipotesis}

Nilai estimasi untuk hubungan jalur dalam model struktural harus signifikan. Sebagai upaya untuk mengetahui signifikansinya adalah melihat t-tabel pada alpha 0,05 $(5 \%)=1,96$, sehingga t-tabel dibandingkan dengan t-statistik. Hipotesis dalam penelitian ini terdiri atas tiga hubungan langsung. Hasil uji hipotesis penelitian ini ditunjukkan pada Tabel 5.

Tabel 5. Hasil Uji Hipotesis

\begin{tabular}{lcccccc}
\hline & Hipotesis & $\begin{array}{c}\text { Original } \\
\text { Sample }\end{array}$ & St.Dev & $\begin{array}{c}\boldsymbol{t} \text { - } \\
\text { statistics }\end{array}$ & $\begin{array}{c}\boldsymbol{p} \text { - } \\
\text { values }\end{array}$ & Keterangan \\
\hline $\begin{array}{l}\text { Loyalitas Supporter } \rightarrow \\
\text { Fanatisme }\end{array}$ & $\mathrm{H} 1$ & 0,574 & 0,072 & 7,962 & 0,000 & Positif, Signifikan \\
\hline $\begin{array}{l}\text { Loyalitas Supporter } \rightarrow \\
\text { Keputusan Pembelian }\end{array}$ & $\mathrm{H} 2$ & 0,731 & 0,047 & 15,689 & 0,000 & Positif, Signifikan \\
\hline $\begin{array}{l}\text { Fanatisme } \rightarrow \text { Keputusan } \\
\text { Pembelian }\end{array}$ & $\mathrm{H} 3$ & 0,137 & 0,077 & 1,773 & 0,077 & $\begin{array}{l}\text { Positif, Tidak } \\
\text { Signifikan }\end{array}$ \\
\hline
\end{tabular}

Sumber: Data primer diolah (2020).

Hasil uji hipotesis menunjukkan bahwa loyalitas supporter memiliki pengaruh positif terhadap fanatisme. Hasil tersebut dapat dilihat pada nilai $p$-values yang menunjukkan nilai 0,000 yang lebih kecil daripada 0,05 dan mengindikasikan bahwa hipotesis kesatu (H1) diterima. Sementara itu, loyalitas supporter mempunyai pengaruh positif terhadap fanatisme. Hal tersebut dapat diketahui dari nilai $p$-values yang menunjukkan nilai $0,000<0,05$. Hasil tersebut diartikan bahwa hipotesis kedua $(\mathrm{H} 2)$ diterima. Uji hipotesis juga menunjukkan bahwa fanatisme tidak mempunyai pengaruh terhadap keputusan pembelian merchandise orisinal Persela Lamongan. Hal tersebut diketahui dari nilai $p$-values yang menunjukkan nilai 0,077 yang lebih besar daripada 0,05, sehingga hasil tersebut menunjukkan hipotesis ketiga (H3) ditolak.

\section{Pembahasan}

\section{Pengaruh Loyalitas terhadap Fanatisme}

Hasil penelitian ini membuktikan bahwa loyalitas supporter Persela Lamongan berpengaruh postif terhadap fanatisme mereka. Perubahan pada loyalitas supporter dapat menyebabkan perubahan pada fanatisme supporter. Semakin tinggi tingkat loyalitas supporter, maka fanatisme juga semakin meningkat. Hasil ini memperkuat penelitian Da Silva dan Casas, (2017) yang menyatakan bahwa loyalitas tim mempunyai pengaruh positif terhadap perilaku konsumsi dan sikap penggemar. Hasil ini menyiratkan bahwa upaya meningkatkan loyalitas tim secara maksimal atau dukungan berbasis penggemar merupakan tujuan penting bagi setiap tim olahraga. Oleh karena itu, loyalitas tim dapat mempengaruhi berbagai kegiatan penggemar dalam pembelian tiket pertandingan tim favorit, menghadiri pertandingan tim favorit sepak bola berulangulang, menonton pertandingan tim favorit dari televisi, berbicara tentang tim favorit, dan berbelanja produk-produk atau merchandise tim favorit (Elahi et al., 2018). 
Semakin setia seorang penggemar kepada suatu tim sepak bola, maka mereka kan semakin terlibat untuk mengonsumsi produk-produk terkait tim tersebut. Penggemar yang sangat setia cenderung melihat pengeluaran mereka sebagai cara untuk mendukung tim idolanya, dan bukan sekedar membayar sejumlah uang untuk mendapatkan barang atau jasa. Hal ini menyebabkan banyak penggemar menjadi kurang sensitif terhadap harga ketika mereka membeli barang dagangan tim atau pemain (Piipponen, 2011). Hasil penelitian ini sesuai dengan temuan Yuniarti dan Ariyanto (2018) bahwa loyalitas dapat menjadikan pelanggan fanatik. Penggemar yang memiliki kesetiaan terhadap sebuah tim dapat berubah menjadi bentuk fanatisme terhadap tim yang dicintainya.

\section{Pengaruh Loyalitas terhadap Pembelian Merchandise Orisinal}

Hasil uji hipotesis menyebutkan bahwa loyalitas supporter memiliki pengaruh positif terhadap keputusan pembelian merchandise orisinal klub Persela Lamongan. Perubahan pada loyalitas supporter akan menimbulkan perubahan pada keputusan pembelian merchandise orisinal klub. Semakin tinggi tingkat loyalitas supporter, maka peningkatan tersebut akan menyebabkan semakin tinggi pula keputusan pembelian merchandise orisinal klub. Hasil ini memperkuat penelitian Wymer dan Rundle-Thiele (2016) yang menyatakan bahwa loyalitas pendukung adalah prediktor yang baik perilaku sukarela mereka. Pendukung yang loyal akan secara sukarela melakukan pembelian terhadap merchandise orisinal yang dikeluarkan oleh tim sepak bola yang didukungnya. Semakin tinggi loyalitas pendukung, maka semakin tinggi pula kecenderungan untuk memutuskan pembelian produk merchandise orisinal yang dikeluarkan oleh klub.

Hasil penelitian ini mendukung pernyataan bahwa loyalitas supporter olahraga penting untuk dicapai, karena penggemar olahraga yang setia adalah konsumen unik. Komitmen mereka terhadap tim olahraga dapat dikatakan tidak tertandingi di sektor bisnis atau rekreasi lainnya (Tapp \& Clowes, 2002). Kesetiaan supporter kepada tim idolanya akan memiliki dampak bagi perkembangan timnya. Loyalitas supporter yang tinggi akan berdampak pada keputusan pembelian merchandhise orisinal. Supporter akan membelanjakan uangnya untuk membeli atribut tim yang dicintainya, apabila ia memiliki loyalitas yang tinggi. Mayoritas responden penelitian ini memiliki penghasilan tertentu. Oleh karena itu, faktor keuangan akan membantu supporter yang loyal untuk membeli merchandhise orisinal klub idolanya.

\section{Pengaruh Fanatisme terhadap Pembelian Merchandise Orisinal}

Hasil uji hipotesis penelitian ini menemukan bahwa fanatisme tidak memiliki pengaruh terhadap keputusan pembelian menchandise orisinal klub sepak bola yang didukungnya. Hasil ini menunjukkan bahwa tinggi rendahnya fanatisme seorang supporter tidak serta merta mendorong terjadinya perubahan pada tingkat keputusan pembelian merchandise orisinal klub. Hasil ini tidak sejalan dengan pernyataan Yoshida et al., (2014) yang menyatakan bahwa perilaku membeli merchandise orisinal merupakan inti peran supporter sebagai kegiatan konsumen yang berkaitan dengan transaksi. Transaksi yang dimaksud adalah pembelian merchandise orisinal klub. Hasil ini bertentangan dengan pendapat Muslich \& Dewi (2017) yang menyimpulkan bahwa fanatisme memiliki pengaruh terhadap perilaku konsumtif supporter Lazio di Surabaya. Kecintaan terhadap sebuah klub sepak bola dapat mendorong seorang supporter untuk membeli produk-produk yang berkaitan dengan klub kesayangannya. Hasil penelitian ini juga 
tidak sejalan dengan pernyataan Belk, (2004), bahwa supporter fanatik sebagai konsumen menunjukkan kekaguman sejati terhadap suatu merek atau produk klub sepak bola yang digemari, wujud pengabdian, semangat, dan antusiasme mereka yang sering dianggap menular untuk menarik pelanggan baru atau supporter baru.

Hasil yang tidak sejalan tersebut bisa terjadi, karena tidak semua supporter yang memiliki fanatisme tinggi terhadap klub Persela Lamongan didukung oleh faktor finansial yang cukup. Strata ekonomi dan latar belakang pendukung Persela Lamongan sangat beragam. Para supporter tersebut, ada yang sudah bekerja, tetapi ada pula yang belum berpenghasilan. Tidak semua pendukung fanatik Persela Lamongan mempunyai kemampuan untuk membeli merchandise orisinal klub yang relatif lebih mahal dibandingkan yang tidak orisinal. Sebagian supporter yang membeli merchandise non-orisinal tetap memiliki fanatisme yang tinggi terhadap tim Persela Lamongan. Supporter Persela yang fanatik tetapi tidak memiliki daya beli yang cukup cenderung lebih mengekspresikan kefanatikannya melalui aksi dukungan di dalam lapangan sepak bola daripada membeli merchandise orisinal. Di sisi lain, ada pula supporter yang sebenarnya tingkat fanatismenya rendah, tetapi ia membeli merchandise orisinal karena mempunyai dukungan finansial yang memadai. Hal ini dapat dilihat dari responden penelitian berstatus pelajar atau mahasiswa yang belum memiliki pendapatan.

\section{KESIMPULAN DAN SARAN}

Berdasarkan hasil uji hipotesis, fanatisme tidak memiliki pengaruh terhadap keputusan pembelian merchandise orisinal klub Persela Lamongan. Namun, loyalitas supporter terbukti berpengaruh positif terhadap fanatisme dan keputusan pembelian merchandise orisinal tersebut. Loyalitas supporter mempunyai pengaruh terhadap fanatisme, karena supporter yang telah lama mendukung Persela Lamongan akan memiliki rasa cinta terhadap klub tersebut, sehingga para supporter tetap akan membela ketika klub mengalami masalah atau menyebabkan suatu masalah. Hal itu menunjukkan bahwa loyalitas telah terkonversi menjadi fanatisme.

Loyalitas supporter juga berpengaruh positif terhadap pembelian merchandise orisinal klub Persela Lamongan. Hasil tersebut membuktikan pentingnya loyalitas supporter bagi klub sepak bola sebagai salah satu faktor penentu sumber pendapatan klub. Oleh karena itu, manajemen klub perlu meningkatkan prestasi klub dan juga meningkatkan kualitas merchandise agar supporter yang loyal lebih berminat untuk membeli merchandise orisinalnya. Hasil penelitian ini perlu ditindaklanjuti untuk memperoleh penjelasan lebih lanjut tentang hubungan fanatisme supporter dan keputusan pembelian merchandise orisinal klub. Jumlah sampel yang relatif kecil (100 responden) merupakan keterbatasan penelitian ini, sehingga penelitian mendatang disarankan untuk memperbesar jumlah sampelnya.

\section{DAFTAR PUSTAKA}

Anam, H. C. \& Supriyadi, S. (2018). Hubungan Fanatisme dan Konformitas terhadap Agresivitas Verbal Anggota Komunitas Supporter Sepak Bola di Kota Denpasar. Jurnal Psikologi Udayana, 5(01), 132-144.

Aswanto, H. K., \& Nurchayati, N. (2020). Pengalaman Perempuan yang Telah Menikah Menjadi Bonita. Character: Jurnal Penelitian Psikologi, 7(1), 2-10. 
Bauer, H. H., Stokburger-Sauer, N. E., \& Exler, S. (2008). Brand Image and Fan Loyalty in Professional Team Sport: A Refined Model and Empirical Assessment. Journal of Sport Management, 22, 202-226, https://doi.org/10.1123/jsm.22.2.205

Belk, R. W. (2004). Men and Their Machines. Advances in Consumer Research, 31, 273-278.

Bristow, D. N., \& Sebastian, R. J. (2001). Holy Cow! Wait 'til Next Year! A Closer Look at the Brand Loyalty of Chicago Cubs Baseball Fans. Journal of Consumer Marketing, 18(3), 256-275. https://doi.org/10.1108/07363760110392976.

Ceritajersey.com (2019). Laskar Joko Tingkir - Persela Lamongan 2019 Home Jersey. Diakses pada tanggal 23 Juni 2020 di https://www.ceritajersey.com/2019/06/ laskar-joko-tingkir-persela-lamongan.html

Chung, E., Beverland, M. B., Farrelly, F., \& Quester, P. (2008). Exploring Consumer Fanaticism: Extraordinary Devotion in the Consumption Context. Advances in Consumer Research, 35, 333-340.

Chung, E., Farrelly, F., Beverland, M. B., \& Karpen, I. O. (2018). Loyalty or Liability: Resolving the Consumer Fanaticism Paradox. Marketing Theory, 18(1), 3-30. https://doi.org/10.1177/1470593117705696.

Cova, B., \& Cova, V. (2002). Tribal Marketing: The Tribalisation of Society and Its Impact on the Conduct of Marketing. European Journal of Marketing, 36(5/6), 595-620. https://doi.org/10.1108/03090560210423023.

Da Silva, E. C., \& Casas, A. L. L. (2017). Sport Fans as Consumers: An Approach to Sport Marketing. British Journal of Marketing Studies, 5(4), 36-48.

Deveci, G., \& Ercis, A. (2017). Determining the Influence of Fanatical Tendencies on Consumption Styles Based on Lifestyles. Marketing and Branding Research, 4(1), 33-49. https://doi.org/10.33844/mbr.2017.60418.

Elahi, A., Mahmoudi, B., \& Yazdi, H. A. (2018). The Impact of Team Reputation and Team Quality on the Loyalty of the Fans of Iranian National Volleyball Team: A Mediating Role of Satisfaction. Annals of Applied Sport Science, 6(4),39-48. https://doi.org/10.29252/aassjournal.6.4.39.

Fillis, I., \& Mackay, C. (2014). Moving Beyond Fan Typologies: The Impact of Social Integration on Team Loyalty in Football. Journal of Marketing Management, 30(34), 334-363. https://doi.org/10.1080/0267257X.2013.813575.

Funk, D., Mahony, D., \& Ridinger, L. (2002). Characterizing Consumer Motivation as Individual Difference Factors: Augmenting the Sports Interest Inventory (SII) to Explain Level of Spectator Support. Sport Marketing Quarterly, 11(1), 33-43.

Ghozali, I. \& Latan, H. (2015). Konsep, Teknik, Aplikasi Menggunakan Smart PLS 3.0 untuk Penelitian Empiris. Semarang: BP Undip.

Habibie, T.N. (2015). Hubungan antara Fanatisme dan Solidaritas Sosial di Komunitas ICI Moratti Regional Malang. Jurnal Mahasiswa Sosiologi, 2(1), 1-32.

Huynh, G., \& Wilson, J. A. J. (2014). Vietnamese Attitudes and Behavioural Patterns towards Counterfeit Brands. ASEAN Marketing Journal, 6(2), 89-104. https://doi.org/10.21002/amj.v6i2.4217.

Johnston, D. (2004). Consumer Loyalty Amongst Sport Fans: AGF Case Study. Thesis (Master Program), Aarhus University, Aarhus, Denmark. 
Kaynak, E., Salman, G. G., \& Tatoglu, E. (2008). An Integrative Framework Linking Brand Associations and Brand Loyalty in Professional Sports. Journal of Brand Management, 15(5), 336-357.

Khuong, M. N., \& Duyen, H. T. M. (2016). Personal Factors Affecting Consumer Purchase Decision towards Men Skin Care Products - A Study in Ho Chi Minh City, Vietnam. International Journal of Trade, Economics and Finance, 7(2), 4450. https://doi.org/10.18178/ijtef.2016.7.2.497.

Kotler, P., \& Keller, K. L (2016). Manajemen Pemasaran. Edisi 12, Jilid 1. Jakarta: PT. Indeks.

Kusuma, Y. B. (2016). Analisis Perilaku Pendukung Wanita Klub Sepakbola di Indonesia, Jurnal Ekonomi dan Bisnis Airlangga, 26(3), 1-22.

Maderer, D., \& Holtbrügge, D. (2019). International Activities of Football Clubs, Fan Attitudes, and Brand Loyalty. Journal of Brand Management, 26(3), 411-426. https://doi.org/10.1057/s41262-018-0136-y.

Mubina, M. F., Amirudin, A., \& Lathifah, A. (2020). Fanatisme dan Ekspresi Simbolik Supporter Sepak Bola Panser Biru dan SNEX Semarang: Kajian Etnografis. Endogami: Jurnal Ilmiah Kajian Antropologi, 3(2), 217-226.

Mahmudah, S., \& Liana, C. (2018). Sejarah Persela Lamongan. Avatara, 6(2), 175-184.

Muslich, M., \& Dewi, N. W. S. P. (2017). Hubungan antara Fanatisme dengan Perilaku Konsumtif pada Supporter Lazio di Surabaya. Jurnal Psikologi UNESA, 7(4),1318.

Phau, I., Sequeira, M., \& Dix, S. (2009). Consumers' Willingness to Knowingly Purchase Counterfeit Products. Direct Marketing, 3(4), 262-281. https://doi.org/10.1108/17505930911000865.

Piipponen, H. (2011). Enhancing Customer Relations in Team Sport Business. Thesis (Master in Marketing). Department of Marketing and Management - School of Economics, Aalto University, Helsinki, Finland.

Redden, J., \& Steiner, C. J. (2000). Fanatical Consumers: Towards a Framework for Research. Journal of Consumer Marketing, 17(4), 322-335. https://doi.org/10.1108/07363760010335349.

Rizki, F. A., \& Utomo, M. A. (2017). Pengaruh Brand Image, Brand Trust, dan Perceived Quality terhadap Brand Loyalty Adidas pada Chelsea Indonesia Supporter Club (CISC) di Depok. Jurnal Ilmu Manajemen Oikonomia, 13(2), 3748.

Rohman, F. (2019). Enhancing Loyalty: Improving the Experience Quality of Indonesian Football Club Fans. Jurnal Aplikasi Manajemen, 17(3), 464-470. https://doi.org/10.21776/ub.jam.2019.017.03.10.

Samra, B., \& Wos, A. (2015). Consumer in Sports: Fan Typology Analysis. Journal of Intercultural Management, 6(4-1), 263-288. https://doi.org/10.2478/joim-20140050 .

Setiawan, Y., \& Saraswati, T. (2017). Perilaku Konsumtif Penggemar Grup Idola JKT48 dalam Fanbase Wani: Studi Kasus terhadap 6 Anggota Fanbase Wani. Japanology, 5(2), 266-279.

Setiadi, J. N. (2003). Perilaku Konsumen: Perspektif Kontemporer pada Motif, Tujuan, dan Keinginan Konsumen. Jakarta: Prenadamedia Group. 
Sulfiyanto, T. (2017). Ini 8 Suporter Paling Fanatik di Sepakbola Indonesia. Diakses pada tanggal 22 Juni 2020 di https://www.indosport.com/sepakbola/20170423/ini8-suporter-paling-fanatik-di-sepakbola-indonesia/la-mania-persela-lamongan.

Tapp, A., \& Clowes, J. (2002). From "Carefree Casuals" to "Professional Wanderers": Segmentation Possibilities for Football Supporters. European Journal of Marketing, 36(11/12), 1248-1269. https://doi.org/10.1108/03090560210445164.

Tenenhaus, M., Vinzi, V. E., Chatelin, Y. M., \& Lauro, C. (2005). PLS Path Modeling. Computational Statistics \& Data Analysis, 48(1), 159-205.

Thorne, S., \& Bruner, G. C. (2006). An Exploratory Investigation of the Characteristics of Consumer Fanaticism. Qualitative Market Research, 9(1), 51-72. https://doi.org/10.1108/13522750610640558.

Tokmak, G., \& Aksoy, R. (2016). Factors Affecting Brand Loyalty in Football: An Application on "The Big Four" Football Clubs in Turkish Super League. International Review of Economics and Management, 4(3), 84-106. https://doi.org/10.18825/irem.01078.

Wicaksono, A. (2019). Klub dengan Jumlah Penonton Terbanyak di Liga 12019. Diakses pada tanggal 22 Juni 2020 di: https://databoks.katadata.co.id/datapublish/2020/02/28/klub-dengan-jumlahpenontonterbanyak-di-liga-1-2019

Wymer, W., \& Rundle-Thiele, S. (2016). Supporter Loyalty: Conceptualization, Measurement, and Outcomes. Nonprofit and Voluntary Sector Quarterly, 45(1),129. https://doi.org/10.1177/0899764014564579.

Yoshida, M., Gordon, B., Nakazawa, M., \& Biscaia, R. (2014). Conceptualization and Measurement of Fan Engagement: Empirical Evidence from a Professional Sport Context. Journal of Sport Management, 28(4), 399-417. https://doi.org/10.1123/jsm.2013-0199.

Yuniarti, Y., \& Ariyanto, A. (2018). Pengaruh Serviscape tehadap Loyalitas Pelanggan Telkomsel. Jurnal Digest Marketing, 3(1), 15-22. 